Research Article

\title{
Experimental Investigation on the Mixture Ratio and Diffusion Performance of Grouting Materials for Water Bursting Prevention in Coal Mines
}

\author{
Huiqing Lian $\left(\mathbb{D},{ }^{1}\right.$ Haiyang Yi $\left(\mathbb{D},{ }^{2}\right.$ Zhenxue Dai $\mathbb{D}^{3},{ }^{3}$ Junwen Yang, ${ }^{1}$ Zhenxing Ji, \\ Ruigang Han, ${ }^{1}$ Lu Meng, ${ }^{1}$ and Yi Yang ${ }^{1}$ \\ ${ }^{1}$ School of Emergency Technology and Management, North China Institute of Science and Technology, Langfang 065201, \\ Hebei, China \\ ${ }^{2}$ School of Safety Supervision, North China Institute of Science and Technology, Langfang 065201, Hebei, China \\ ${ }^{3}$ College of Construction Engineering, Jilin University, Changchun 130026, China
}

Correspondence should be addressed to Haiyang Yi; haiyangyi@ncist.edu.cn

Received 26 March 2021; Accepted 24 May 2021; Published 3 June 2021

Academic Editor: Xianjie Hao

Copyright (C) 2021 Huiqing Lian et al. This is an open access article distributed under the Creative Commons Attribution License, which permits unrestricted use, distribution, and reproduction in any medium, provided the original work is properly cited.

Grouting is a common and important technique for water bursting prevention in coal mines; the success of grouting in coal mines depends highly on the flowability of grouting materials and the strength of the hardened body as well. In this paper, a series of performance tests, in terms of the water-cement ratio, viscosity, drainage rate, presetting time, final setting time, compressive strength, and permeability were conducted on the cement-fly ash-based grout at various mixture ratios. The evolution of these performances versus different mixture ratios was analyzed; targeting at the reasonable flowability and hardened strength of grouting materials, an optimized mixture ratio was recognized for water bursting prevention in coal mines. Furthermore, the diffusion experiments of optimized grout material were designed taking into account the influence of confining and hydraulic pressure in the porous medium. As a result, the confining and hydraulic pressures have a linear negative correlation with the diffusion distance of grout materials. These results have guiding significance to water bursting prevention in coal mines.

\section{Introduction}

Grouting is a well-known approach to preventing water bursting in coal mines [1-3]. As it is a massive work for water grouting sealing in coal mines, pipe blockage is not allowed during the grouting processes whereas water grouting sealing is expected to be soon as possible, the strength of the hardened body is desired to be reasonable against stratum movement, and the contents of grouting materials are hoped to be of low cost and available nearby. Obviously, these demands in engineering practice depend on the mixture ratio of raw materials in grouting materials and their diffusion performance as well $[4,5]$.

The commonly used grouting materials in coal mines are divided into two categories: the cement-based and the chemical grouts $[6,7]$. The cement-based grout is widely available, but its poor grout ability is due to high viscosity and weak durability and limited its practical applications in engineering to some extent [8-10]. Thus, many efforts were made to improve the cement-based materials by chemical approach, such as adding urethanes, acrylates, lignans, and resins [11-18]. In recent years, fly ash has been recognized as a favorable additive for the cementbased grout to enhance the flowability and durability of grouting materials. Furthermore, it reduces the costs of grouting materials and environmental contamination [19-22]. It is notable that the increasing content of fly ash increases the flowability, but reduces the compressive strength of hardened grouts [23-25]. Therefore, an optimized mixture ratio needs to be determined to balance the flowability and strength of fly ash-cement-based grouting materials. 
Abundant works have been carried out on the mixture ratio of fly ash-cement-based grouting materials. Through laboratory experiments, researchers studied the rheological and mechanical performances of fly ash-cement-based grouting materials at various mixture ratios. Mirza et al. [26] studied the flowability, drying shrinkage, and stability of high-volume fly ash grout. Çınar et al. [27] determined the marsh cone flow time of cement-based grout while adding different amount of fly ash. Li et al. [1] studied the viscosity of cement-based grout mixed with microfine fly ash. Akbulut and Saglamer [28] evaluated the influence of fly ash associated with clay on the fluidity of grout materials. Xu et al. [29] measured the viscosity and compressive strength of cement-based grouts mixture with fly ash and clay by orthogonal tests. Cui et al. [30] tested the setting time (the duration of solidification of grouting materials) of fly ashpromoted cement-based grouting mixtures. Zhang et al. [31] modified the mixture ratio of cement-sodium silicate materials to satisfy the gelation time in concrete cracks reparation. Watterson and Siggard [32] investigated the compressive and time-dependent strength of fly ash-modified grouts. These studies provided reasonable mixing ratios of fly ash-cement-based grouts, resulting in adequate rheological and mechanical properties of grout materials. Most of the previous studies focused on the pumpability of slurry; however, in the practical implementation of grouting into the aquifers to prevent water bursting in coal mines, the diffusion performance of grouting mixtures plays a key role in designing the arrangements of grouting holes [33-35].

The diffusion of fly ash-cement-based grouting materials has been revealed to be better than pure cement formula. Feng et al. [36] tested the diffusion of fly ash-cement-based grouting material in the real coal mine, and the results showed that the diffusion radius of injecting fly ash-promoted cement-based grouting materials is approximately $10 \mathrm{~m}$ longer than that of the pure cement slurry. Li et al. [37] suggested that different content of the mixtures in grouting materials produce various migration resistances in mine aquifer. Additionally, Wang et al. [38] pointed out that the stress field in aquifer is a notable influence factor on seepage of the grouting materials. If the stress of porous medium was neglected, the diffusion areas would be approximately concentric circles in cross section at various hydraulic pressures [39]. However, the stress changes the permeability of porous medium in different directions, thereby deducing different diffusion conditions along various directions [40-42]. Therefore, the stress conditions should be taken into account while studying the diffusion of grouting material. Unfortunately, insufficient attention has been paid to this aspect, and rare studies have been found.

The paper implemented a series of orthogonal experiments and laboratory tests to get the evolution rule of grout properties with various content proportions, and an optimal proportion makes an adequate flowability and compressive strength for the grout. Additional physical model tests were conducted to analyze the diffusion mechanism of the grouting processes under different conditions of confining stress and hydraulic pressure, providing practical guidance to the grouting engineering in coal mines.

\section{An Orthogonal Experiment}

2.1. Orthogonal Experiment Design. The orthogonal experiment is a design method that considers multifactor level combination, which reduces workload but ensures the quality and accuracy of the test results. Materials involved in the orthogonal experiment contain Portland cement ( $\mathrm{P} \mathrm{O}$ 425), coal ash, and sodium silicate $\left(\mathrm{Na}_{2} \mathrm{O} \cdot \mathrm{nSiO}_{2}\right)$. The Portland cement has a density of about $3.1 \mathrm{~g} / \mathrm{cm}^{3}$ and its main components contain $3 \mathrm{CaO} \cdot \mathrm{SiO}_{2}, 2 \mathrm{CaO} \bullet \mathrm{SiO}_{2}$, $4 \mathrm{CaO} \bullet \mathrm{Al}_{2} \mathrm{O}_{3} \bullet \mathrm{Fe}_{2} \mathrm{O}_{3}$, and $3 \mathrm{CaO} \bullet \mathrm{Al}_{2} \mathrm{O}_{3}$. The coal fly ash used is classified category I according to the Chinese standard GB1596-91, of which the granularity and the density are smaller than $0.04 \mathrm{~mm}$ and about $1.15 \mathrm{~g} / \mathrm{cm}^{3}$, respectively. The sodium silicate has a density of around $1.354 \mathrm{~g} / \mathrm{ml}$ and a Baume degree of $37.9^{\circ}$ Bé.

The factors involved in the orthogonal experiment are defined to be the water-to-cement mixing ratio (factor $A$ ), the coal ash content (factor $B$ ), and the sodium silicate content (factor $C$ ). Additionally, four levels of each factor were set in the experiment. According to the theory of orthogonal design, the $\mathrm{L}_{16}\left(4^{5}\right)$ method is acceptable to represent the influence of factors. Therefore, as listed in Table 1, the $\mathrm{L}_{16}\left(4^{5}\right)$ method was applied in the orthogonal experiment, the water-to-cement mixing ratios (factor $A$ ) were defined as $0.8: 1,1: 1,2: 1$, and $3: 1$, the contents of coal ash (factor $B$ ) were set as $10 \%, 20 \%, 30 \%$, and $40 \%$, and $0 \%$, $1 \%, 3 \%$, and $5 \%$ were selected for the sodium silicate contents (factor $\mathrm{C}$ ). Factors $\mathrm{E}$ and $\mathrm{F}$ are empty columns in the orthogonal design table. The tested materials are identified by $S 1$ to $S 16$, and the alphabet $S$ means slurry and 16 kinds of slurry were tested.

The test facilities involve an electronic balance, measuring cups, a viscometer, a Vicat apparatus, a rock compression test machine, and a permeability test system. In the orthogonal experiment, the physical and mechanical performance of grout materials and its hardened form were obtained, where the density, viscosity, drainage rate, and setting time were tested for the grout materials, and the compressive strength and permeability determined the hardened grout mass. Nine indexes were defined for the performance tests as D1 (density, g/ml), D2 (viscosity, $\mathrm{MPa} \cdot \mathrm{s}), \mathrm{D} 3$ (draina ge rate, \%), D4 (presetting time, h), D5 (final setting time, h), D6 (tensile strength, MPa), D7 (compressive strength at the 7th day, MPa), D8 (compressive strength at the 14 th day, MPa), D9 (permeability at the 15 th day, $10^{-3} \mu \mathrm{m}^{2}$ ), D10 (compressive strength at the 28th day, $\mathrm{MPa}$ ), and D11 (permeability at the 28th day, $10^{-3} \mu \mathrm{m}^{2}$ ).

2.2. Experiment Results. There are 144 data in total obtained from the performance tests (see Table 2), and these data help finding out the primary factors from $A, B$, and $C$ (described in Table 1), the effectiveness of individual factor, and the optimal level of each factor; the detailed optimization process will be introduced in Section 2.3.

According to Table 2, the average value of bleeding rate, presetting time, and final setting time versus various factor levels are plotted in Figure 1(a) to Figure 1(c), respectively. 
TABLE 1: The design of orthogonal experiment according to the $\mathrm{L}_{16}\left(4^{5}\right)$ method.

\begin{tabular}{|c|c|c|c|c|c|}
\hline \multirow[b]{2}{*}{ Material ID } & \multicolumn{5}{|c|}{ Factors } \\
\hline & $\begin{array}{c}A \\
\text { (water- } \\
\text { cement) }\end{array}$ & $\begin{array}{c}B \\
\text { (fly ash) }\end{array}$ & $\begin{array}{c}C \\
\text { (sodium } \\
\text { silicate) }\end{array}$ & $\begin{array}{c}E \\
(-)\end{array}$ & $\begin{array}{l}F \\
(-)\end{array}$ \\
\hline S1 & A1 $(0.8: 1)$ & B1 (10\%) & C1 $(0 \%)$ & 1 & 1 \\
\hline S2 & $\mathrm{A} 1(0.8: 1)$ & $\begin{array}{c}\text { B2 } \\
(20 \%)\end{array}$ & C2 (1\%) & 2 & 2 \\
\hline S3 & A1 $(0.8: 1)$ & $\begin{array}{c}\text { B3 } \\
(30 \%)\end{array}$ & C3 (3\%) & 3 & 3 \\
\hline S4 & A1 $(0.8: 1)$ & $\begin{array}{c}\text { B4 } \\
(40 \%)\end{array}$ & C4 (5\%) & 4 & 4 \\
\hline S5 & A2 $(1: 1)$ & B1 (10\%) & C2 (1\%) & 3 & 4 \\
\hline S6 & A2 $(1: 1)$ & $\begin{array}{c}\text { B2 } \\
(20 \%)\end{array}$ & C1 $(0 \%)$ & 4 & 3 \\
\hline S7 & A2 $(1: 1)$ & $\begin{array}{c}\text { B3 } \\
(30 \%)\end{array}$ & C4 (5\%) & 1 & 2 \\
\hline S8 & A2 $(1: 1)$ & $\begin{array}{c}\text { B4 } \\
(40 \%)\end{array}$ & C3 (3\%) & 2 & 1 \\
\hline S9 & A3 $(2: 1)$ & B1 $(10 \%)$ & C3 (3\%) & 4 & 2 \\
\hline S10 & A3 $(2: 1)$ & $\begin{array}{c}\text { B2 } \\
(20 \%)\end{array}$ & C4 (5\%) & 3 & 1 \\
\hline S11 & A3 $(2: 1)$ & $\begin{array}{c}\text { B3 } \\
(30 \%)\end{array}$ & C1 (0\%) & 2 & 4 \\
\hline S12 & A3 $(2: 1)$ & $\begin{array}{c}\text { B4 } \\
(40 \%)\end{array}$ & C2 (1\%) & 1 & 3 \\
\hline S13 & A4 $(3: 1)$ & B1 (10\%) & C4 (5\%) & 2 & 3 \\
\hline S14 & A4 $(3: 1)$ & $\begin{array}{c}\text { B2 } \\
(20 \%)\end{array}$ & C3 (3\%) & 1 & 4 \\
\hline S15 & A4 $(3: 1)$ & $\begin{array}{c}\text { B3 } \\
(30 \%)\end{array}$ & C2 (1\%) & 4 & 1 \\
\hline S16 & A4 $(3: 1)$ & $\begin{array}{c}\text { B4 } \\
(40 \%)\end{array}$ & C1 (0\%) & 3 & 2 \\
\hline
\end{tabular}

The factors $A, B$, and $C$ were uniformly renamed as $t$ in Figure 1 , and the subscripts 1 to 4 were kept as that of $A, B$, and $C$ in Table 1.

Figure 1 indicates that the higher the water-cement ratio, the larger the bleeding rate, presetting time, and final setting time. On the contrary, the bleeding rate, presetting, and final setting time slightly reduce with the increase of the sodium silicate content. Obviously, the content of fly ash has limited influence on the hardening process, exhibiting stable level of presetting (see Figure 1(b), about $12 \mathrm{~h}$ ), and final setting time (see Figure 1(c), approximately $24 \mathrm{~h}$ ) at different contents of fly ash, but the higher content of fly ash enlarged the bleeding rate as plotted in Figure 1(a).

The compressive strengths of mixtures at different setting times are displayed in Figure 2. The compressive strengths are weakened by the increasing water-cement ratio, contents of fly ash, and sodium silicate in all cases. A rapid decline in compressive strength was observed with the increasing contents of sodium silicate from Figure 2(c), which implies that the sodium silicate content has the greatest impact on the compressive strength of materials at the 28th day. The permeability of materials has slight changes at various water-cement ratios, fly ash contents, and sodium silicate contents, except the one when the watercement ratio exceeds $2: 1$, exhibiting a small increase.
Figure 3 shows the measured permeability of materials at 15th day and 28th day. As it is displayed in Figure 3(a), the change of permeability is obvious when the water-cement ratio is larger than $2: 1$, exhibiting raised permeability from about $1.3 \times 10^{3} \mathrm{~m}^{2}$ to $2.210^{3} \mathrm{um}^{2}$. While the content of fly ash and sodium silicate has little influence on the permeability of materials, see Figures 3(b) and 3(c), and the fluctuated range of measured permeability is about $0.4 \times 10^{3} \mathrm{um}^{2}$.

The grout mixtures are typical non-Newtonian fluid; thus, their viscosities were evaluated with elapsed time. According to Table 2, the viscosities of S1 to S4 and S7 were difficult to be measured in the performance tests because the mixed slurry were too thick to flow in the tests. In order to analyze the influence of the water-cement ratio, fly ash content, and sodium silicate content on the evolution of viscosity within presetting time, the viscosities of S8 to S15 were tested within 12 minutes, and the measured data were plotted in Figure 4.

Figure 4 suggests that the viscosities of tested grouting materials were increased versus time. Obviously, the influence of the water-cement ratio on the viscosity of grouting material is significant, according to the data of S8 (watercement ratio $1: 1$ ) and alternative data; the smaller the value of the water-cement ratio (higher content of cement), the larger the viscosity of grouting materials. Additionally, when the water-cement ratio is within $2: 1$ and the content of sodium silicate is over 3\% (e.g., the tested material is named S8, S9, and S10), the viscosity of grouting material increased quickly. In such case, the grouting material will flow slowly in the porous medium.

As analyzed above, the elevated water-cement ratio reduces the viscosity of grouting materials, while it reduces the strength of hardened grout body as plotted in Figure 2(a), this means higher water-cement ratio benefits its flowability but weakens its strength. Therefore, it is a necessary to optimize the factor levels to find a reasonable mixture ratio, thereby satisfying the demands of grouting materials for water bursting in coal mines.

2.3. Determination of the Mixture Ratio. In the engineering case of water bursting prevention in coal mining, the good grouting materials are those which have a low viscosity, a relatively long presetting time, a high compressive strength, and a low permeability. Due to the limited influence the grout density has on the grouting processes, it was not considered in the optimization analysis.

According to the analysis in Section 2.2, a water-cement ratio over $2: 1$ and the contents of sodium silicate ranged within $3 \%$ are beneficial to the grout diffusion due to its lower viscosity which allows a faster waterproof efficiency of the grout. Figures 2(a) and 3(a) convince us that the compressive strength was reduced by the high water-cement ratio and the permeability of hardened grout mass was increased when the water-cement ratio is over $2: 1$; therefore, the proper water-cement ratio should be $2: 1$.

As it was analyzed in Section 2.2, the content of fly ash has slight influence on the presetting time, final setting time, permeability, and viscosity of grout materials, but the 


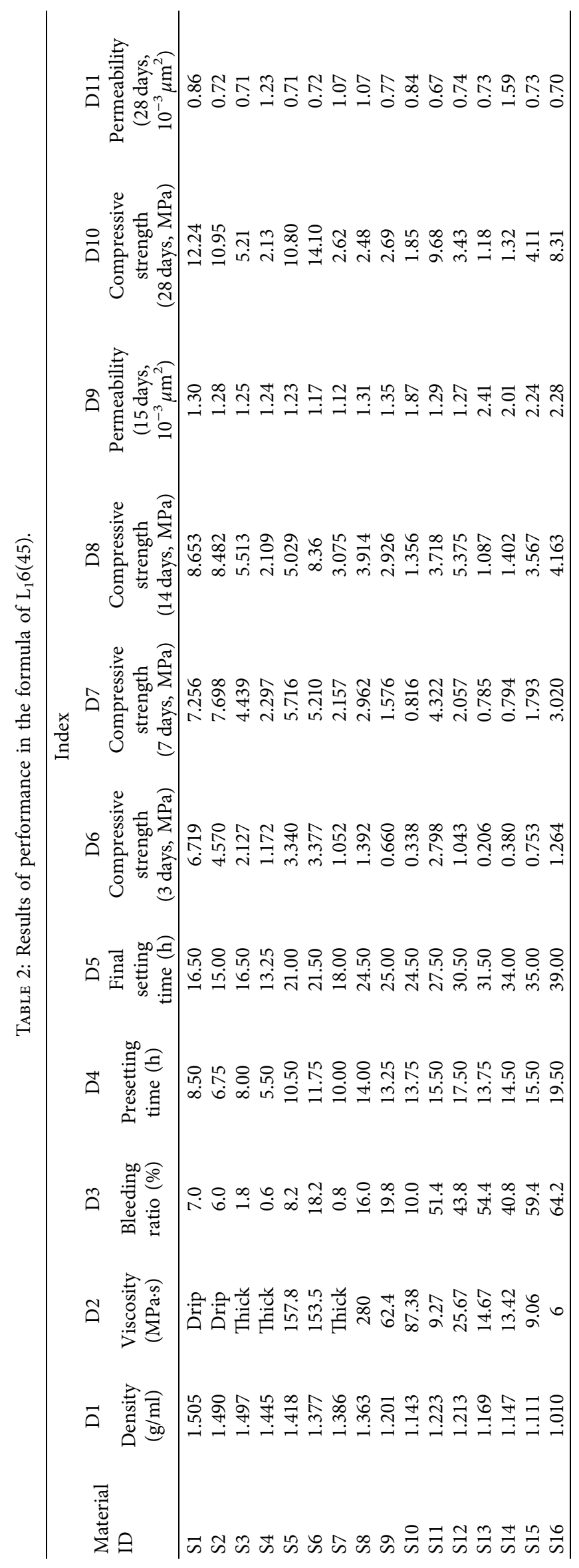




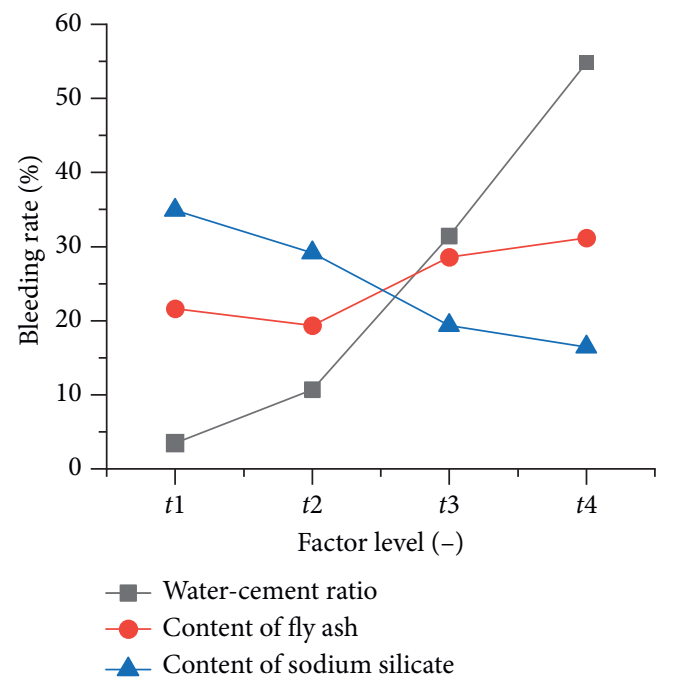

(a)

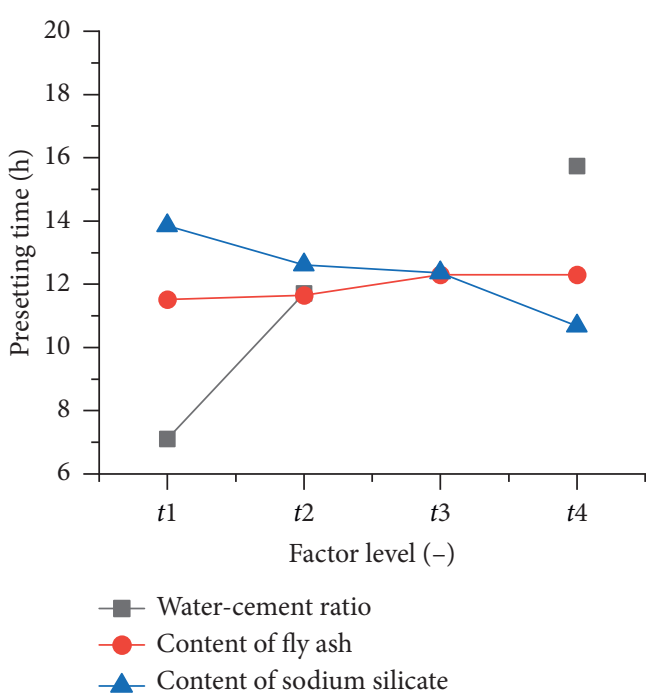

(b)

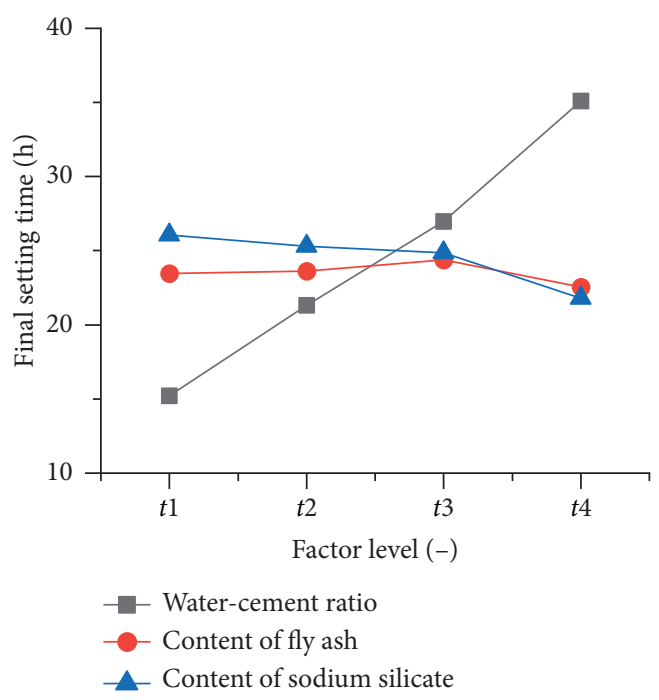

(c)

FIgURE 1: Measured (a) bleeding rate, (b) presetting time, and (c) final setting time at various factor levels.

compressive strength of hardened grout material changed obviously with different contents of fly ash (see Figure 2(b)); interestingly, the grout material with $20 \%$ fly ash has good compressive strength after 14th day; therefore, the content of fly ash in the mixture should be $20 \%$.

According to Figures 1(a), 1(b), and 2(c), the content of sodium silicate mainly control the drainage rate, presetting time, and compressive strength of grout materials and high content of sodium silicate decreases presetting time and compressive strength continuingly, as shown in Figures 1(b) and 2(c). The longer presetting time and higher compressive strength of grout materials are the major concerns in coal mines; according to the experiment data in Figures 1(b) and 2(c), no sodium silicate is reasonable, but in particular engineering practice, a slightly increased viscosity of grout material in a short term helps sealing the rock fracture during the initial duration of grouting work, thereby preventing grout leakage and letting grouting material arrived at the target aquifer. According to the viscosity data of S9 to S12 in Figure 4, when the content of sodium silicate surpassed $1 \%$, the viscosity of grout materials increased slightly in a short time. Combining the demands of high compressive strength and leakage prevention, it is reasonable to set the content of sodium silicate to be $1 \%$.

In summary, the optimal ratio of grout is the watercement mixing ratio of $2: 1$, fly ash content of $20 \%$, and sodium silicate content of $1 \%$.

\section{Laboratory Simulation of Grout Diffusion}

3.1. Experimental Scheme Design. In order to investigate the diffusion rule of optimized grout material at various confining and water pressures, laboratory experiments were launched through an experiment device, as displayed in Figure 5. This device consists of four parts, the test platform, the loading system, the water pressure system, and the grouting system. The 


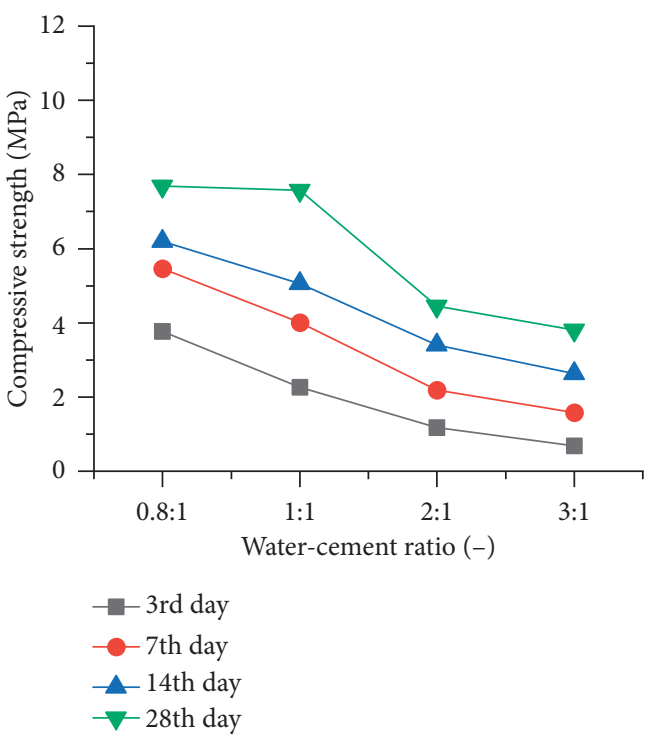

(a)

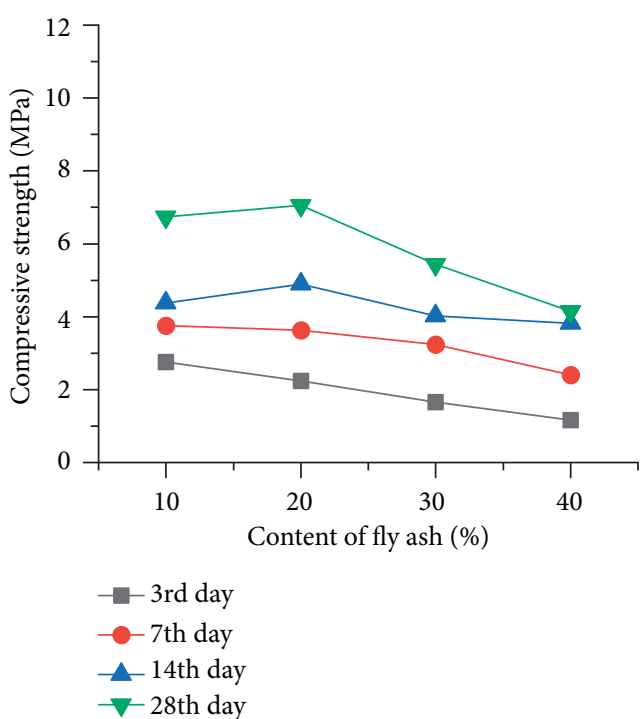

(b)

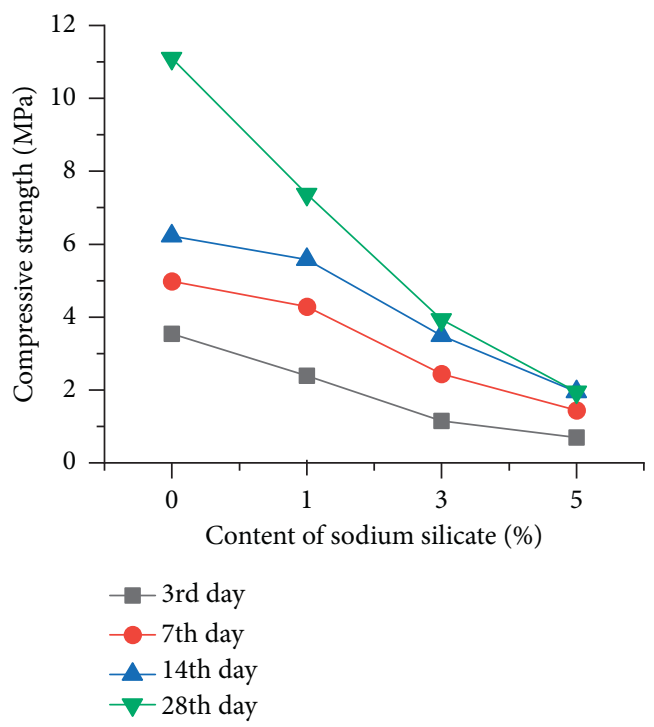

(c)

Figure 2: Measured compressive strength at different (a) water-cement ratios, (b) fly ash contents, and (c) sodium silicate contents.

test platform is a cylindrical steel drum with a height of $60 \mathrm{~cm}$ and an inner diameter of $40 \mathrm{~cm}$, which can be sealed and pressurized. A hydraulic pump is used in the loading system to load the earth pressure. The water pressure system is composed of a nitrogen tank with a certain pressure and a water pressure tank with water and gas pressures. The nitrogen tank pushes water into the simulation device to provide the required water pressure during the experiment.

The yellow sand was selected and screened as the porous medium, and six stainless steel pipes with a diameter of $6 \mathrm{~mm}$ were utilized in the experiment. As shown in Table 3, the water pressure was set with 3 levels while confining pressure keeps constant, and the confining pressure was set with 3 levels when water pressure is constant. The grouting pressure is controlled at 1-1.5 times of the confining pressure.
3.2. Analysis of Experimental Results. In order to investigate the dominant direction of the grout diffusion and the maximum diffusion distance in each experiment. The measurements of the grouting pipe (6 in Figure 5(a)) were shown in Table 4 . For the convenience of analysis, the diffusion directions were defined in the Cartesian coordination, and the direction along the grouting pipe is defined as $Y$ direction, as shown in Figure 6(b); in cross section of the grouting pipe, the horizontal direction is defined as $X$ direction, and the vertical direction is the $Z$ direction. Theoretically, the diffusion area should be cylinder-shaped in the homogenous porous medium, but the hardened grout mass, as plotted in Figure 6, did not match this shape, which maybe caused by the inhomogeneous pore distribution or the influence of confining pressure. The measured diffusion distances versus 


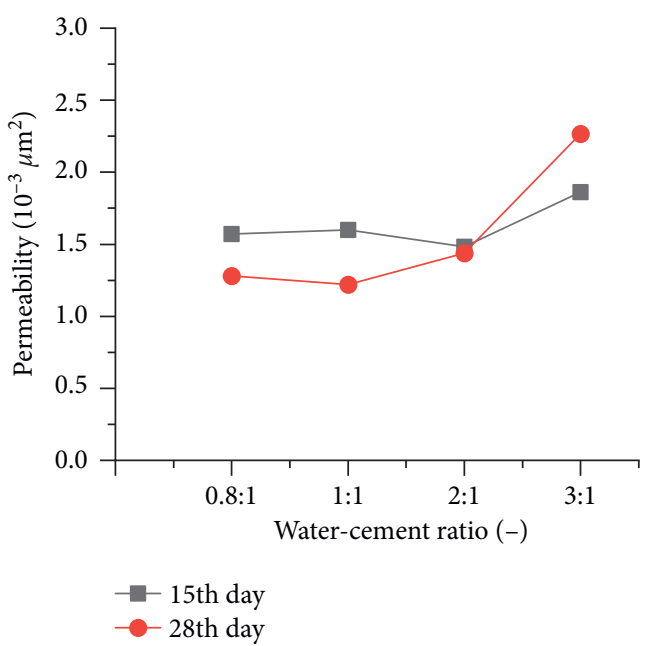

(a)

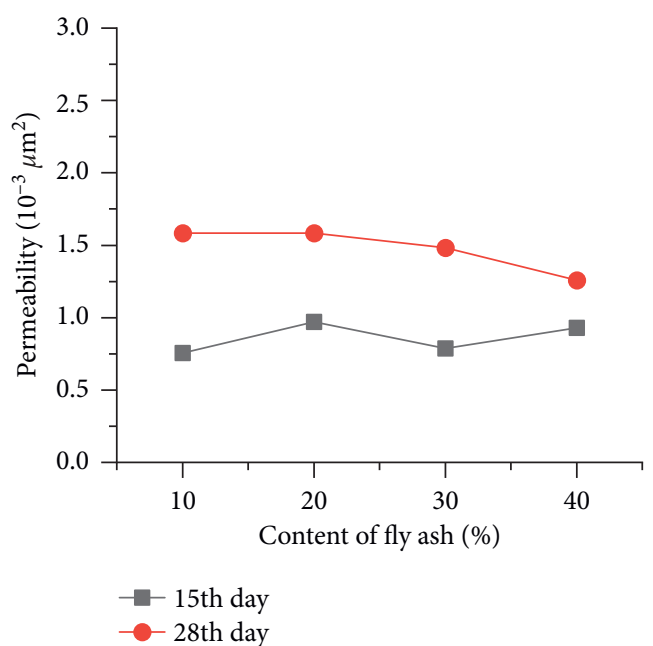

(b)

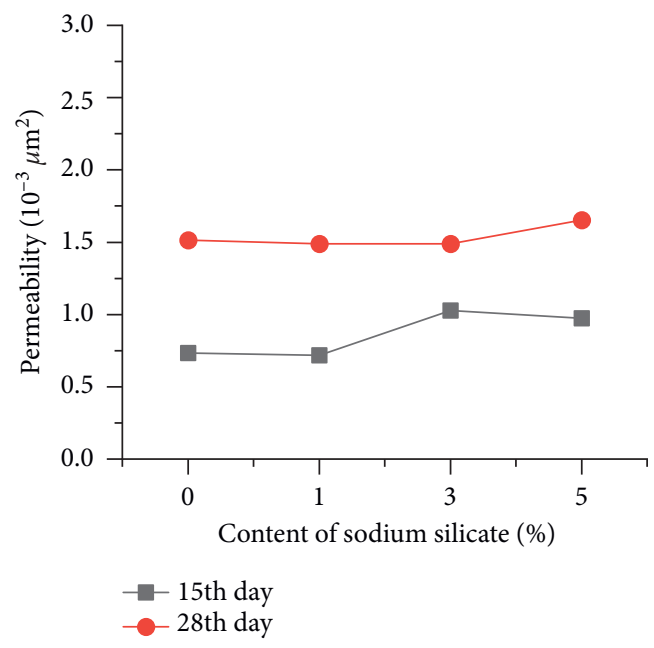

(c)

FIgURE 3: Measured permeability at different (a) water-cement ratios, (b) fly ash contents, and (c) sodium silicate contents.

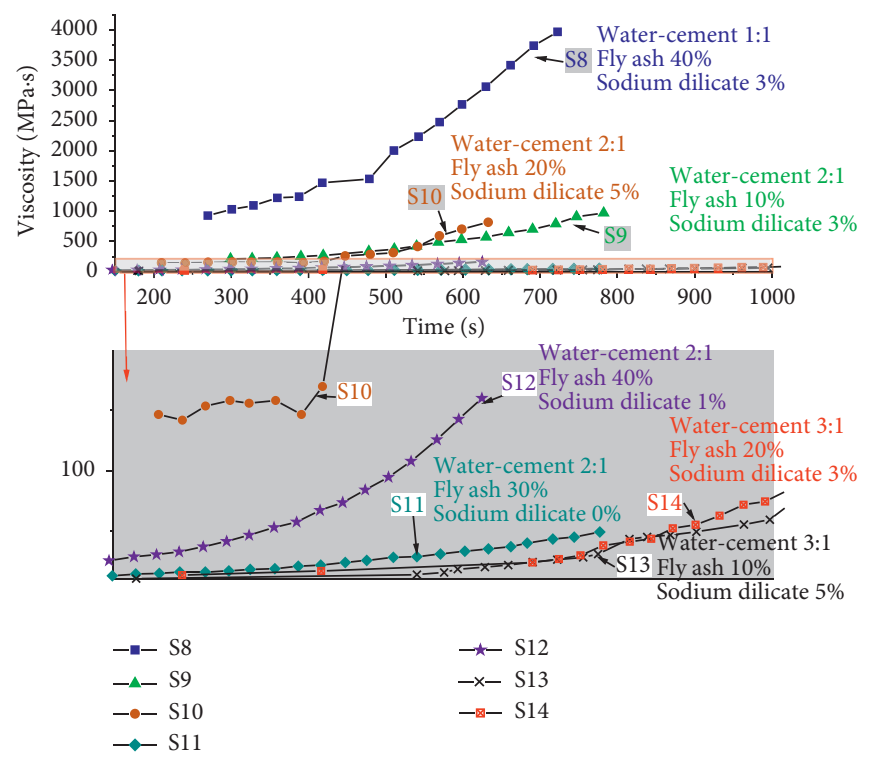

Figure 4: Measured viscosity values. 


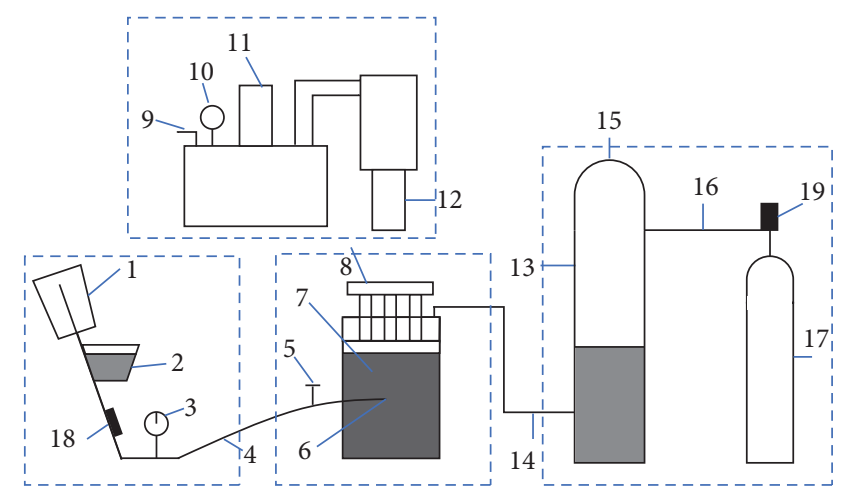

(a)

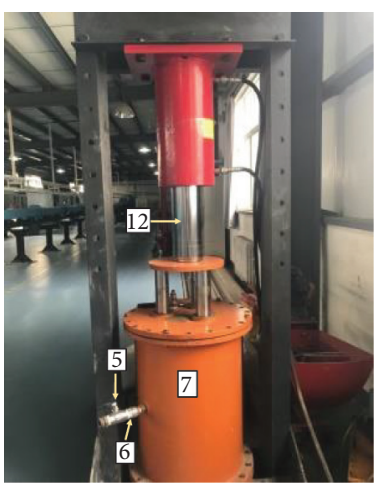

(b)

Figure 5: The experiment system of diffusion (a) diagram of devices and (b) experiment field. 1: electronic motor. 2: slurry tank. 3: pressure gauge. 4: soft pipe. 5: valve. 6: grout pipe. 7: loading platform. 8: load plug. 9: hydraulic valve. 10: pressure gauge. 11: hydraulic pump. 12: jack. 13: water tank. 14: water pipe. 15: water inlet. 16: nitrogen pipe. 17: nitrogen tank. 18: screw pump. 19: gas valve.

TABLE 3: The loading pressure in diffusion experiments.

\begin{tabular}{lccc}
\hline Specimen ID & Grouting pressure (MPa) & $\begin{array}{c}\text { Experimental parameters } \\
\text { Confining pressure (MPa) }\end{array}$ & Hydraulic pressure (MPa) \\
\hline DS1 & 1 & 1 & 0 \\
DS2 & 1 & 1 & 0.5 \\
DS3 & 1 & 1 & 1 \\
DS4 & 2 & 1 & 0.5 \\
DS5 & 2 & 1.5 & 0.5 \\
DS6 & 2 & 2 & 0.5 \\
\hline
\end{tabular}

TABLE 4: Measured diffusion distance.

\begin{tabular}{lccccccc}
\hline $\begin{array}{l}\text { Grout } \\
\text { mass ID }\end{array}$ & $\begin{array}{c}\text { Hydraulic } \\
\text { pressure }(\mathrm{MPa})\end{array}$ & $\begin{array}{c}\text { Confining } \\
\text { pressure }(\mathrm{MPa})\end{array}$ & $\begin{array}{c}\text { Grouting } \\
\text { pressure }(\mathrm{MPa})\end{array}$ & $\begin{array}{c}Z(+) \text { distance } \\
(\mathrm{mm})\end{array}$ & $\begin{array}{c}Z(-) \text { distance } \\
(\mathrm{mm})\end{array}$ & $\begin{array}{c}X(+) \text { distance } \\
(\mathrm{mm})\end{array}$ & $\begin{array}{c}X(-) \text { distance } \\
(\mathrm{mm})\end{array}$ \\
\hline DS1 & 0 & 1 & 1 & 50.81 & 30.25 & 41.26 & 39.62 \\
DS2 & 0.5 & 1 & 1 & 48.59 & 27.15 & 39.83 \\
DS3 & 1 & 1 & 1 & 46.61 & 24.91 & 37.63 & 37.17 \\
DS4 & 0.5 & 1 & 2 & 40.58 & 20.88 & 31.69 & 35.41 \\
DS5 & 0.5 & 1.5 & 2 & 37.42 & 15.47 & 27.31 & 26.28 \\
DS6 & 0.5 & 2 & 2 & 25.74 & 9.81 & 18.54 \\
\hline
\end{tabular}

different hydraulic and confining pressures are plotted in Figures $7(\mathrm{a})$ and $7(\mathrm{~b})$, respectively.

In Table 4 and Figure 7, the $Z(+)$ direction means the positive direction alone $Z$ direction, as plotted in Figure 6. $Z(-), X(+)$, and $X(-)$ have the similar definition as $Z(+)$, and it is notable that the measurement of distance along $Z(-)$ direction is close to the bottom of drum, where the porous water is more difficult to be drained than the area above the grout pipe. Thus, the diffusion distance in $Z(+)$ has the biggest value whereas that in $Z(-)$ direction amounts the smallest one, the diffusion distances alone in $X(+)$ and $X(-)$ directions are close to each other.

As a whole, the diffusion distance of grout formulation has a negative-linear correlation $\left(R^{2}\right.$ of linear fitting line ranged from 0.906 to 0.999 , as shown in Figure $7(a))$ with hydraulic pressure, indicating that the larger the hydraulic pressure and confining pressure, the smaller diffusion distance. The diffusion distance in Figure 7(b) convince us that the higher confining pressure the shorter diffusion distance, and it means that the stress condition in the porous medium is negatively correlated to the diffusion of grouting materials. This may be explained by the pores compressed by the stress, thereby inducing higher diffusion resistance. Figure 7 indicates that the absolute value of the slope in Figure $7(\mathrm{~b})$ is large than that in Figure 7(a), which means the diffusion distances of grout in different directions are more likely to be affected by the confining pressure than by the water pressure. 


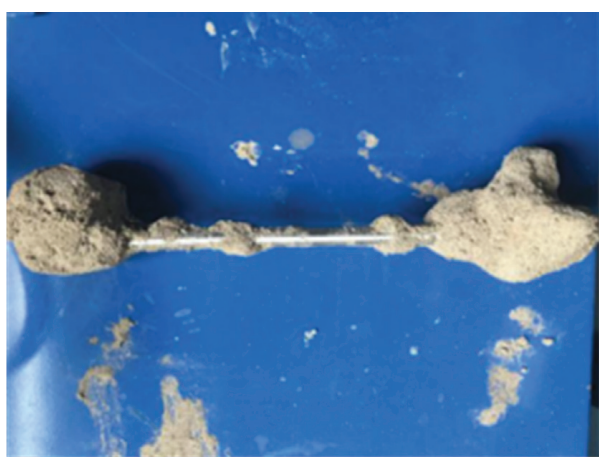

(a)

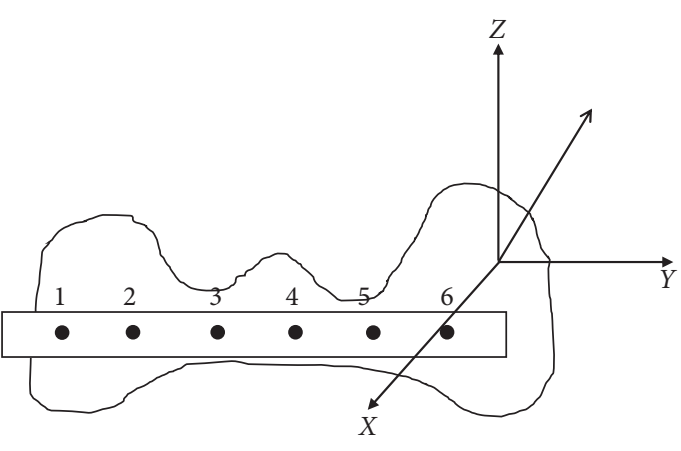

(b)

FIgURE 6: (a)The hardened grout mass and (b) its cross section.

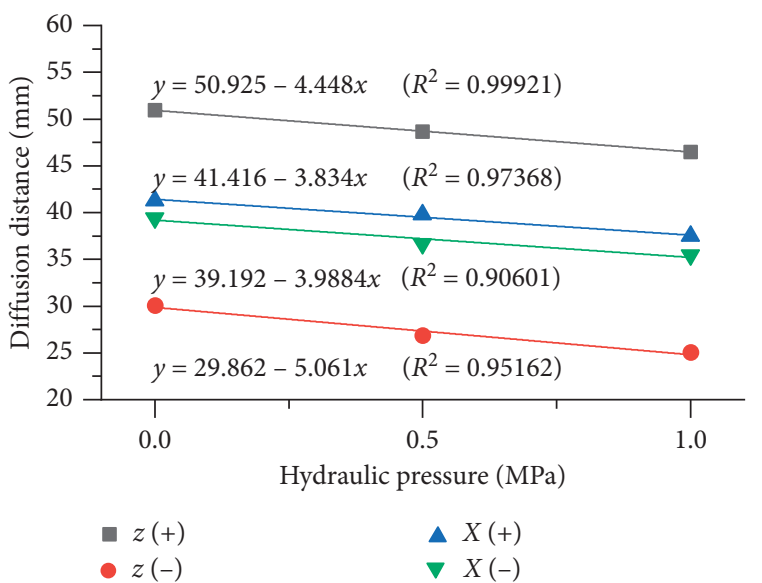

(a)

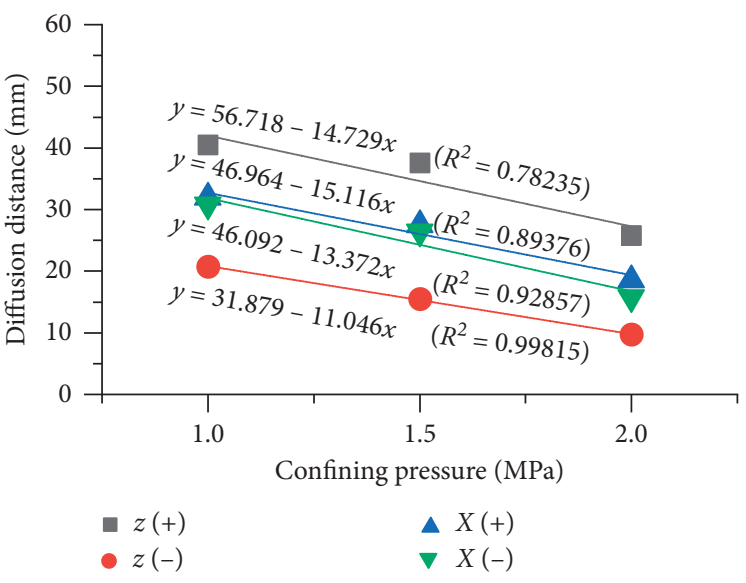

(b)

FIgURE 7: Measured diffusion distances versus (a)hydraulic pressure and (b)confining pressure.

\section{Conclusion}

A series of performance tests and diffusion experiments were implemented to investigate the mixture ratio and diffusion properties of the cement-fly ash-based grout materials for water bursting prevention in coal mining. According to the analysis on the results of performance tests and diffusion experiment, it is concluded that (1) the water-cement ratio is the primary influence factor on the viscosity, drainage rate, final setting time, and compressive strength within 7 days and previous permeability (within 15 days) of grout materials, while additive fly ash do limited effort on the performance of grout materials, except the permeability of hardened grout mass. (2) According to the orthogonal analysis, in order to get a grout material characterized by low viscosity, longer presetting time but shorter final setting time, larger compressive strength, and low permeability, the mixture ratio was suggested by the water-cement ratio of $2: 1,20 \%$ fly ash, and $1 \%$ sodium silicate. (3) The results of diffusion experiment suggest that the confining pressure and hydraulic pressure in the porous medium have negative and linear influence on the diffusion distance of grouting materials, namely, the higher the confining pressure and hydraulic pressure, the shorter the diffusion distance.

\section{Data Availability}

The data for used to support the findings of the study are included within the article.

\section{Conflicts of Interest}

The authors declare that there are no conflicts of interest.

\section{Acknowledgments}

This study was supported by the National Key R\&D Program of China (2017YFC0804108), National Science Foundation of China (51774136 and 52004090), Natural Science Foundation of Hebei Province of China (D2017508099 and E2020508025), and the Program of Education Department of Hebei Province (QN2019320). The authors would also like to thank the Program for Innovative Research Team in the University sponsored by Ministry of Education of China (IRT-17R37) for their 
financial support and the Central University Scientific Research Program (3142014018 and 3142019019).

\section{References}

[1] S. Li, F. Sha, R. Liu, Z. Li, and Q. Zhang, "Investigation of viscous behaviour and strength of microfine-cement-based grout mixed with microfine fly ash and superplasticiser," Advances in Cement Research, vol. 29, no. 5, pp. 206-215, 2017.

[2] Y. Hu, J. Sun, W. Liu, and D. Wei, "The evolution and prevention of water inrush due to fault activation at working face no. II 632 in the Hengyuan coal mine," Mine Water and the Environment, vol. 38, no. 1, pp. 93-103, 2019.

[3] H. R. Gui, D. Reddy, and L. H. Sun, "A review of technological development in water hazards control in China coalmines," International Journal of Earth Sciences and Engineering, vol. 9, no. 5, pp. 1863-1868, 2016.

[4] S. C. Li, J. W. Bai, R. T. Liu, Z. F. Li, H. J. Zhang, and H. T. Wang, "Development and application research of grouting material in mine aquifer transformation," in Proceeding of the Fourth Geo-China International Conference, pp. 126-134, Shandong, China, July 2016.

[5] W. Zhang, X. Zhu, S. Xu, Z. Wang, and W. Li, "Experimental study on properties of a new type of grouting material for the reinforcement of fractured seam floor," Journal of Materials Research and Technology, vol. 8, no. 6, pp. 5271-5282, 2019.

[6] B. Song, S. Zhang, D. Zhang et al., "Inorganic cement grouting for reinforcing triangular zone of highly gassy coal face with large mining height," Energies, vol. 11, no. 10, p. 2549, 2018.

[7] Q. Zhang, X.-M. Hu, M.-Y. Wu, Y.-Y. Zhao, and C. Yu, "Effects of different catalysts on the structure and properties of polyurethane/water glass grouting materials," Journal of Applied Polymer Science, vol. 135, no. 27, p. 46460, 2018.

[8] C. Zhang, J. Yang, J. Fu, X. Ou, Y. Xie, and X. Liang, "Performance evaluation of modified cement-sodium silicate grouting material for prereinforcing loose deposit tunnels," Journal of Materials in Civil Engineering, vol. 31, no. 7, Article ID 06019003, 2019.

[9] C. A. Anagnostopoulos, G. Sapidis, and E. Papastergiadis, "Fundamental properties of epoxy resin-modified cement grouts," Construction and Building Materials, vol. 125, pp. 184-195, 2016.

[10] F. Zhou, W. Sun, J. Shao, L. Kong, and X. Geng, "Experimental study on nano silica modified cement base grouting reinforcement materials," Geomechanics and Engineering, vol. 20 , no. 1 , pp. 67-73, 2020.

[11] A. Cinar and N. Maerz, "An experimental study of chemical grouting materials for optimum mechanical performance," in Proceedings of the Geo-Congress 2020: Foundations, Soil Improvement, and Erosion, American Society of Civil Engineers, Virginia, NV, USA, February 2020.

[12] R. Zullo, L. Verdolotti, B. Liguori et al., "Effect of rheology evolution of a sustainable chemical grout, sodium-silicate based, for low pressure grouting in sensitive areas: urbanized or historical sites," Construction and Building Materials, vol. 230, Article ID 117055, 2020.

[13] X. Gao, X. Wang, and X. Liu, "New chemical grouting materials and rapid construction technology for inclined shaft penetrating drift-sand layer in coal mine," Advances in $\mathrm{Ma}$ terials Science and Engineering, vol. 2018, Article ID 2797419, 5 pages, 2018.

[14] M. Mollamahmutoğlu, E. Avci, S. K. Tomaç, and D. A. Köse, "Performance of novel chemical grout in treating sands,"
Journal of Materials in Civil Engineering, vol. 29, no. 10, Article ID 04017164, 2017.

[15] K. Zheng, X. Yang, R. Chen, and L. Xu, "Application of a capillary crystalline material to enhance cement grout for sealing tunnel leakage," Construction and Building Materials, vol. 214, pp. 497-505, 2019.

[16] Y. Yang, Z. Cui, X. Li, and H. Deng, "Development and materials characteristics of fly ash-slag-based grout for use in sulfate-rich environments," Clean Technologies and Environmental Policy, vol. 18, no. 3, pp. 949-956, 2016.

[17] Y. Wei, F. Wang, X. Gao, and Y. Zhong, "Microstructure and fatigue performance of polyurethane grout materials under compression," Journal of Materials in Civil Engineering, vol. 29, no. 9, Article ID 04017101, 2017.

[18] Y. A. Cinar, The Importance of Chemical Grouting Materials for Optimum Mechanical Performance with Different Soil Conditions, Missouri University of Science and Technology, Rolla, MI, USA, 2018.

[19] R. Drochytka and M. Michalčíková, "Utilization of fluidized bed combustion fly ash in the design of reuse clay soil in the form of self-compacting grouts," Materials, vol. 13, no. 8, p. 1972, 2020.

[20] M. A. Glinicki, D. Jóźwiak-Niedźwiedzka, and M. Dąbrowski, "The influence of fluidized bed combustion fly ash on the phase composition and microstructure of cement paste," Materials, vol. 12, no. 17, p. 2838, 2019.

[21] H. Güllü, A. Cevik, K. M. A. Al-Ezzi, and M. E. Gülsan, “On the rheology of using geopolymer for grouting: a comparative study with cement-based grout included fly ash and cold bonded fly ash," Construction and Building Materials, vol. 196, pp. 594-610, 2019.

[22] F. Sha, S. Li, R. Liu, Z. Li, and Q. Zhang, "Experimental study on performance of cement-based grouts admixed with fly ash, bentonite, superplasticizer and water glass," Construction and Building Materials, vol. 161, pp. 282-291, 2018.

[23] T. M. Do, H.-K. Kim, M.-J. Kim, and Y.-S. Kim, "Utilization of controlled low strength material (CLSM) as a novel grout for geothermal systems: laboratory and field experiments," Journal of Building Engineering, vol. 29, Article ID 101110, 2020.

[24] Z.-Q. Yang, C. Liu, Y. Dong, L.-M. Dou, and J.-K. Wu, "Study on properties of grouting materials and reinforcement effect in coal roadways influenced by dynamic pressure," Geotechnical and Geological Engineering, vol. 37, no. 4, pp. 3329-3342, 2019.

[25] Z. He, Q. Li, J. Wang, N. Yin, S. Jiang, and M. Kang, "Effect of silane treatment on the mechanical properties of polyurethane/water glass grouting materials," Construction and Building Materials, vol. 116, pp. 110-120, 2016.

[26] J. Mirza, M. S. Mirza, V. Roy, and K. Saleh, "Basic rheological and mechanical properties of high-volume fly ash grouts," Construction and Building Materials, vol. 16, no. 6, pp. 353-363, 2002.

[27] M. Çınar, M. Karpuzcu, and H. Çanakc1, "Effect of waste marble powder and fly ash on the rheological characteristics of cement based grout," Civil Engineering Journal, vol. 5, no. 4, pp. 777-788, 2019.

[28] S. Akbulut and A. Saglamer, "Evaluation of fly ash and clay in soil grouting," in Grouting and Ground TreatmentAmerica Society of Civil Engineers, Virginia, NV, USA, 2003.

[29] G. Q. Xu, J. P. Yan, and X. L. Xia, “Optimization experiment on mixing ratio of new grouting material to prevent mine floor water inrush," Coal Science and Technology, vol. 38, no. 12, pp. 22-24, 2010. 
[30] J. Cui, W. Zhang, X. Ji, and G.-A. Ji, "Study on performance of fly ash slag cement grouting materials," IOP Conference Series: Earth and Environmental Science, vol. 267, no. 3, Article ID 032012, 2019.

[31] B. Zhang, F. Gao, X. Zhang, Y. Zhou, B. Hu, and H. Song, "Modified cement-sodium silicate material and grouting technology for repairing underground concrete structure cracks," Arabian Journal of Geosciences, vol. 12, no. 22, p. 680, 2019.

[32] S. M. Watterson and K. Siggard, "Compressive and timedependent strength of concrete masonry constructed with type $\mathrm{M}$ mortar and grouts containing high volume of fly ash and slag," ACI Materials Journal, vol. 113, no. 2, pp. 185-195, 2016.

[33] S. Cao, G. Li, Q. Yao, and F. Wang, "Prediction of quantity of water inrush from coal seam floor and its reinforcement technique by grouting," Chinese Journal of Rock Mechanics and Engineering, vol. 28, no. 2, pp. 312-318, 2009.

[34] S.-C. Li, F. Xu, Q.-Q. Zhang, L.-P. Li, W.-M. Wang, and H.-L. Liu, "Analysis and construction techniques for a water seal for underground mines subjected to water inrush," Mine Water and the Environment, vol. 35, no. 2, pp. 168-179, 2016.

[35] C. Yang, H. B. Bai, Y. Jiao, and H. L. Li, "An establishment about the floor strata strengthened by grouting system," Electron Journal of Geotech Engineering, vol. 18, pp. 12471254, 2013.

[36] Y.-L. Feng, L. Liang, L.-H. Duan, and J.-L. Li, "Researching on grouting material in Chensilou coal mine," Materials Research Innovations, vol. 19, no. 5, pp. S5-S454, 2015.

[37] S. Li, R. Liu, Q. Zhang, and X. Zhang, "Protection against water or mud inrush in tunnels by grouting: a review," Journal of Rock Mechanics and Geotechnical Engineering, vol. 8, no. 5, pp. 753-766, 2016.

[38] H. Wang, H. Liu, R. Liu et al., "Numerical simulation on seepage law and thickness of reinforcing ring of mine Ordovician aquifer," in Proceeding of the International Conference on Mechatronics and Intelligent Robotics, pp. 268-274, Springer, Kunming, China, May 2017.

[39] C. Jiang, Z. Jiang, S. Liu, Q. Sun, and C. Yang, "Chemical grout diffusion in porous rock based on response of geoelectric field," International Journal of Mining Science and Technology, vol. 23, no. 5, pp. 643-646, 2013.

[40] F. Celik, "The observation of permeation grouting method as soil improvement technique with different grout flow models," Geomechanics and Engineering, vol. 17, no. 4, pp. 367-374, 2019.

[41] Z. Zhou, X. Du, S. Wang, X. Cai, and L. Chen, "Micromechanism of the diffusion of cement-based grouts in porous media under two hydraulic operating conditions: constant flow rate and constant pressure," Acta Geotechnica, vol. 14, no. 3, pp. 825-841, 2019.

[42] B. S. Du and L. Ma, "Application of comprehensive reinforce technology in soft and crumbly surrounding rock in high stress," Advanced Materials Research, vol. 393, pp. 603-618, 2012. 